\title{
Voltammetric Behaviour of Hesperidin at a Composite Graphite Electrode ${ }^{\dagger}$
}

\author{
Nimet Numan *, Iulia Gabriela David, Mihaela Buleandră, Dana Elena Popa \\ and Emilia Elena Iorgulescu
}

Department of Analytical Chemistry, Faculty of Chemistry, University of Bucharest, 90-92 Panduri Av., District 5, 050633 Bucharest, Romania; gabrielaiulia.david@g.unibuc.ro (I.G.D.); mihaela.buleandra@g.unibuc.ro (M.B.); elena.popa@chimie.unibuc.ro (D.E.P.); emilia-elena.iorgulescu@g.unibuc.ro (E.E.I.)

* Correspondence: numannimet097@gmail.com

+ Presented at the 16th International Symposium "Priorities of Chemistry for a Sustainable Development" PRIOCHEM, Bucharest, Romania, 28-30 October 2020.

Published: 13 November 2020

Keywords: flavonoid; hesperidin; voltammetry; composite graphite electrode; disposable

Flavonoids are natural antioxidants with important roles in plant growth and human health. They are polyphenols with a benzene- $\gamma$-pyrone structure, the hydroxyl groups grafted on the conjugated benzene rings being responsible for their antioxidant and electrochemical activity. Thus, electrochemical studies on the electrode reactions of these compounds can give a significant insight into their action mechanism as antioxidants [1]. Hesperidin (HESP) is a flavone glycoside found predominantly in the peel of citrus fruits. Literature reports voltammetric determination of HESP on mercury or different carbon-based electrodes [2], but none of the studies refers to the cost-effective and easy-to-use pencil graphite electrode (PGE) (Figure 1). This work presents for the first time HESP voltammetric behaviour at PGE.

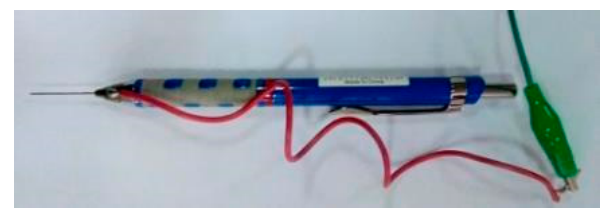

Figure 1. The composite pencil graphite electrode (PGE).

An amount of $10^{-3}$ M HESP stock solution was daily prepared by dissolving the proper amount of HESP in $2 \mathrm{~mL} 0.2 \mathrm{M} \mathrm{NaOH}$ and subsequent dilution with bidistilled water to $10 \mathrm{~mL}$. The working solutions were obtained by successive dilutions of the stock solution with the corresponding supporting electrolyte. A PC running GPES 4.9 software and the Autolab PGSTAT 12 system equipped with a three-electrode cell (working electrode: PGE) were used for voltammetric recordings.

The voltammetric response of HESP was investigated by differential pulse voltammetry (DPV) at different working electrodes ( $\mathrm{Pt}$, glassy carbon, and PGE with different types of pencil leads). Graphite leads are composite materials consisting of graphite powder $(\sim 60 \%)$, clay $(\sim 30 \%)$, and a binder (resin or a high polymer) [3]. The hardness of the composite graphite leads $(2 \mathrm{H}, \mathrm{H}, \mathrm{HB}, 2 \mathrm{~B}$, and $\mathrm{B}$ ) decreases when the graphite content is higher. The harder $\mathrm{H}$ type graphite composite material exhibited the highest sensitivity $\left(0.743 \mathrm{~A} \times \mathrm{L} / \mathrm{mol} \times \mathrm{cm}^{2}\right)$ for HESP voltammetric determination. PGE potentiostatic/potentiodynamic electrochemical activation in different media did not enhance the HESP DPV signal. Both oxidation signals of HESP were shifted towards lower 
potential values when the solution $\mathrm{pH}$ was increased indicating that an equal number of electrons and protons are involved, the highest DPV signals being recorded in Britton Robinson Buffer $\mathrm{pH}$ 1.81. HESP cyclic voltammograms present a controlled diffusion oxidation peak at about $0.78 \mathrm{~V}$ and signal at about $0.48 \mathrm{~V}$ due to a diffusion-adsorption-controlled reduction in HESP oxidation product in the first scan.

The highest and best-shaped voltammetric response of HESP was observed at type $\mathrm{H}$ composite leads, having a lower graphite content. HESP oxidation is $\mathrm{pH}$-dependent and diffusion-controlled, involving an equal number of electrons and protons.

Acknowledgments: This work was supported by University of Bucharest, research grand number 20045/2018.

\section{References}

1. Masek, A.; Zaborski, M.; Chrzescijanska, E. Electrooxidation of flavonoids at platinum electrode studied by cyclic voltammetry. Food Chem. 2011, 127, 699-704.

2. Sims, M.J.; Li, Q.; Kachoosangi, R.T.; Wildgoose, G.G.; Compton, R.G. Using multiwalled carbon nanotube modified electrodes for the adsorptive striping voltammetric determination of hesperidin. Electrochim. Acta 2009, 54, 5030-5034.

3. David, I.; Popa, D.; Buleandra, M. Pencil graphite electrodes: A versatile tool in electroanalysis. J. Anal. Methods Chem. 2017, 2017, 1905968.

Publisher's Note: MDPI stays neutral with regard to jurisdictional claims in published maps and institutional affiliations.

(C) 2020 by the authors. Licensee MDPI, Basel, Switzerland. This article is an open access article distributed under the terms and conditions of the Creative Commons Attribution (CC BY) license (http://creativecommons.org/licenses/by/4.0/). 